\title{
Synthesis, Aggregation Behavior, and Photodynamic Properties of a Water-Soluble Fulleropyrrolidine Bearing an $N$-PEG Pyridinium Unit
}

\author{
Keiji Mizuki, ${ }^{* a}$ Seigo Matsumoto ${ }^{a}$ Taro Honda, ${ }^{a}$ Kouhei Maeda, ${ }^{a}$ Satoshi Toyama,${ }^{a}$ \\ Daisuke Iohara, ${ }^{b}$ Fumitoshi Hirayama, ${ }^{b}$ Shoko Okazaki, ${ }^{b}$ Keizo Takeshita, ${ }^{b}$ and Taizo Hatta ${ }^{a}$ \\ ${ }^{a}$ Department of Nanoscience, Faculty of Engineering, Sojo University; 4-22-1 Ikeda, Nishi-ku, Kumamoto 860-0082, \\ Japan: and ${ }^{b}$ Faculty of Pharmaceutical Sciences, Sojo University; 4-22-1 Ikeda, Nishi-ku, Kumamoto 860-0082, \\ Japan.
}

Received March 12, 2018; accepted May 27, 2018

Herein, we describe the synthesis of a water-soluble photodynamically active fullerene bearing a polyethylene glycol chain and a hydrophilic cationic group, revealing that the solubility of the above derivative in aqueous medium depends on ultrasonication time, with the particle size of aggregates being correlated with concentration.

Key words fullerene derivative; polyethylene glycol; photodynamic activity

Nano-size carbon materials can potentially be applied in various fields, particularly in biochemistry and biomedicine. ${ }^{1-5)}$ For example, fullerene $\mathrm{C}_{60}$ is known to exhibit unique antibacterial, ${ }^{6,7)}$ antitumor, ${ }^{8,9)}$ and antioxidant activity. ${ }^{10)}$ However, in order for these properties to be efficiently utilized, $\mathrm{C}_{60}$ derivatives need to be water-soluble. A number of strategies for imparting water solubility to $\mathrm{C}_{60}$ are known, e.g., the introduction of water-solubilizing substituents such as carboxylic acid ${ }^{11,12)}$ or polyethylene glycol groups ${ }^{13,14)}$ and the formation of supramolecular complexes with water-soluble host molecule(s) such as cyclodextrin(s). ${ }^{15,16)}$ However, watersoluble fullerenes prepared by the above methods often form aggregates or precipitates, which decreases the efficiency of generating activated oxygen in aqueous solution.

In recent years, drug delivery systems utilizing enhanced permeation and retention effects, such as those based on macromolecules and micelles, have attracted much attention due to being able to suppress side effects induced by drug dispersion. ${ }^{17-19)}$ However, despite the above progress, the aggregation of fullerene derivatives in water and their biomedical applica-

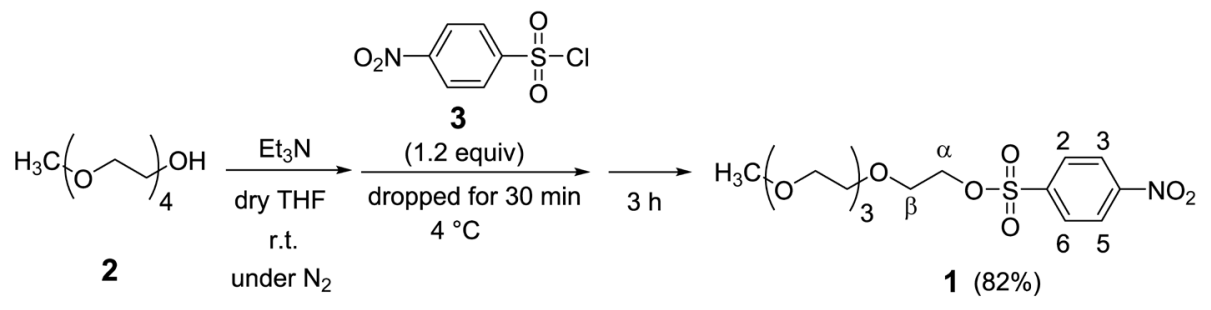

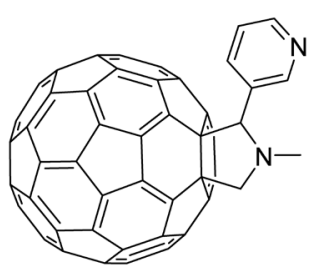

4

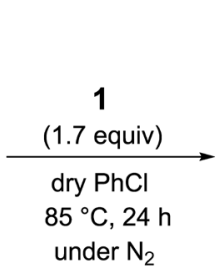

under $\mathrm{N}_{2}$

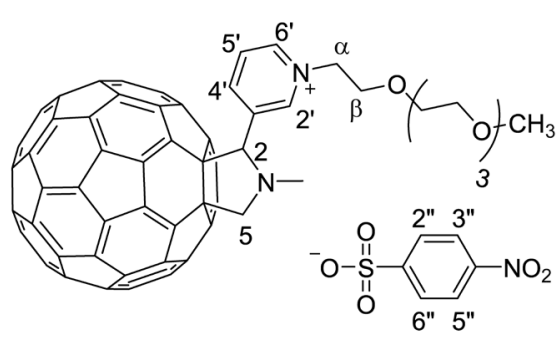

$5(85 \%)$

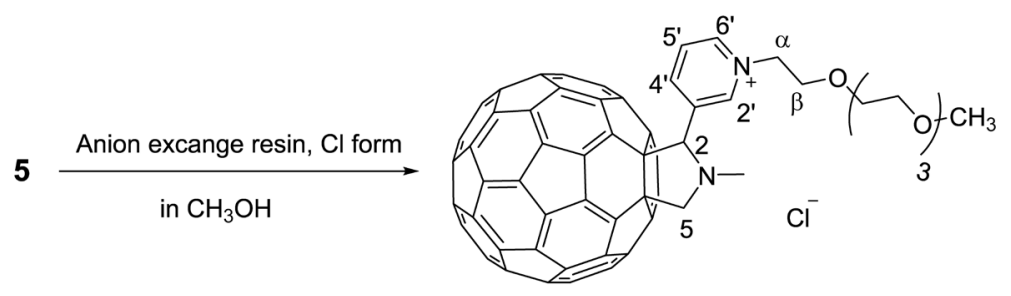

WSF (quant.)

Chart 1. 


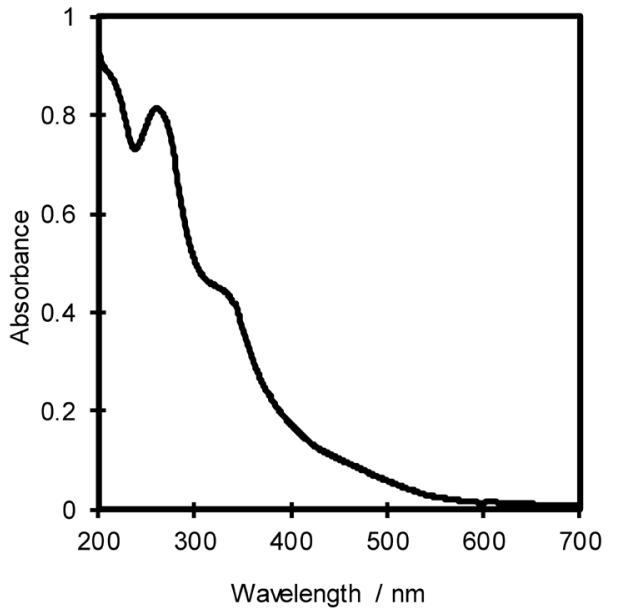

Fig. 1. UV-Vis Spectrum of WSF in $\mathrm{H}_{2} \mathrm{O}(7.83 \mu \mathrm{M})$

tions have been insufficiently investigated.

Herein, we synthesized a novel water-soluble fulleropyrrolidine bearing an $N$-polyethylene glycol (PEG) pyridinium unit (denoted as WSF) and correlated its water solubility with ultrasonication time and aggregate size, additionally examining photodynamic activity.

\section{Results and Discussion}

The synthesis of WSF is shown in Chart 1. PEGylation reagent 1 was synthesized from tetraethylene glycol monomethyl ether $\mathbf{2}$ and $p$-nitrobenzenesulfonyl chloride $\mathbf{3}$ in dry tetrahydrofuran (THF) in the presence of triethylamine, being subsequently reacted with fulleropyrrolidine $4^{20}$ in chlorobenzene at $85^{\circ} \mathrm{C}$ to afford precursor $\mathbf{5}$ in moderate yield. Finally, anion-exchange of $\mathbf{5}$ on Dowex $1 \mathrm{X} 8 \mathrm{Cl}$-form furnished WSF in quantitative yield.

The molar absorption coefficient of WSF in ethanol (at $254 \mathrm{~nm}$ ) was determined as $102000 \mathrm{~L} \mathrm{~mol}^{-1} \mathrm{~cm}^{-1}$. Next, WSF was dispersed in water upon ultrasonication (Branson B-1200, $60 \mathrm{~W}, 47 \mathrm{kHz}$ ) performed at room temperature to $40^{\circ} \mathrm{C}$, and the obtained dispersion was shaken at $200 \mathrm{rpm}$ for $1 \mathrm{~h}$ at $25^{\circ} \mathrm{C}$ and centrifuged at $10000 \mathrm{rpm}$ for $1 \mathrm{~h}$ and the supernatant was obtained. After the above operation was repeated three times, the final supernatant was characterized by UV-Vis spectrometry (Fig. 1). Specifically, the supernatant $(4 \mathrm{~mL})$ was freezedried, and the residue was dissolved in ethanol, with the concentration of WSF in water calculated based on the absorption of the ethanolic solution.

As a result, the solubility of WSF in water was correlated with ultrasonication time, with saturation $(60-80 \mu \mathrm{M})$ observed after $12 \mathrm{~h}$ (Fig. 2).

After solubility determination, we evaluated the particle size of WSF aggregates by dynamic light scattering (DLS) analysis using the Marquardt method. WSF was confirmed to form aggregates in water, with the average particle size under sonication-free conditions equaling $c a .338 \mathrm{~nm}$ and decreasing with increasing sonication time. Despite the same sonication time, solutions of different concentrations were obtained, which confirmed the dependence of particle size on the concentration of WSF (Fig. 3). Additionally, we investigated the temporal stability of WSF aggregates prepared by 12-h ultrasonication, with the almost unchanged particle size implying aggregate stability (Fig. 4).

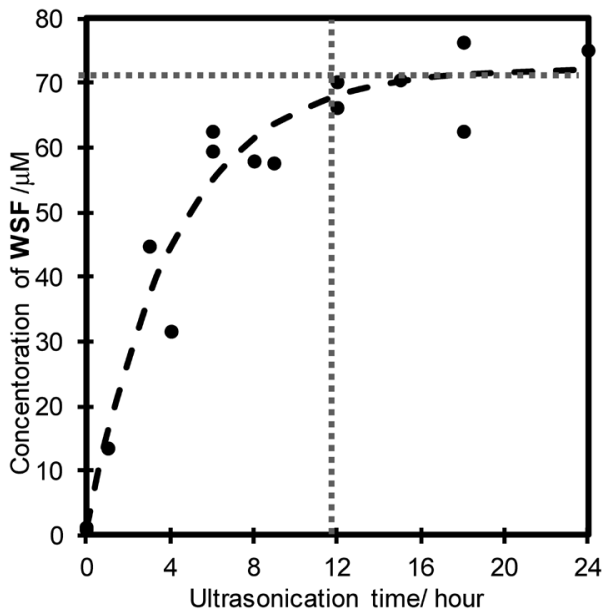

Fig. 2. Correlation between Ultrasonication Time and WSF Concentration

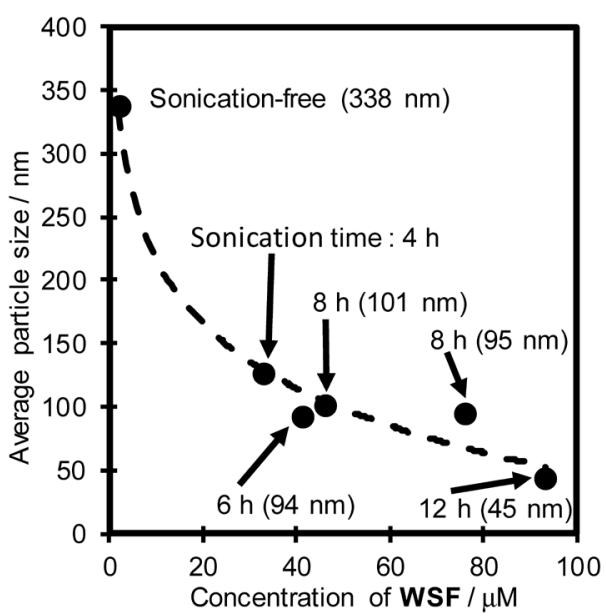

Fig. 3. Correlation between WSF Concentration and Particle Size of Aggregates

Next, phosphate buffer (10mm, pH 7.4) was added to an appropriate amount of WSF, sonicated for $15 \mathrm{~min} \times$ times (ULTRASONIC CLEANER MODEL US-100, $50 \mathrm{kHz}, 100 \mathrm{~W}$, total $75 \mathrm{~min})$, centrifuged for $1 \mathrm{~h}\left(9100 \times \boldsymbol{g}, 25^{\circ} \mathrm{C}\right)$, and the supernatant was collected to prepare a WSF buffer solution. The concentration was determined to be $4 \mu \mathrm{M}$ by absorbance and molar extinction coefficient. On the other hand, the particle size was not reproducible in DLS measurement, unfortunately. It was guessed that the aggregate size changes in a short time because of the solvent polarity enhancement by the buffer solution.

The photodynamic activity of WSF was evaluated using A549 cells, which were seeded in 96-well culture plates and incubated for $24 \mathrm{~h}$ in Dulbecco's modified Eagle's medium containing $10 \%$ fetal calf serum. WSF solutions of various concentrations were added to each well, and the cells were cultured for $24 \mathrm{~h}$, washed twice with phosphate buffered saline, irradiated with a Xenon lamp $\left(35 \mathrm{~mW} / \mathrm{cm}^{2}, 400-700 \mathrm{~nm}\right)$ for $0.5 \mathrm{~h}$, and incubated for further $24 \mathrm{~h}$. Subsequently, cell viability was determined using the WST-1 assay, with the obtained results revealing that the toxicity of WSF increased with its concentration. The cytotoxicity of WSF solution in the dark was observed above about $20 \mu \mathrm{M}$, which may be due 

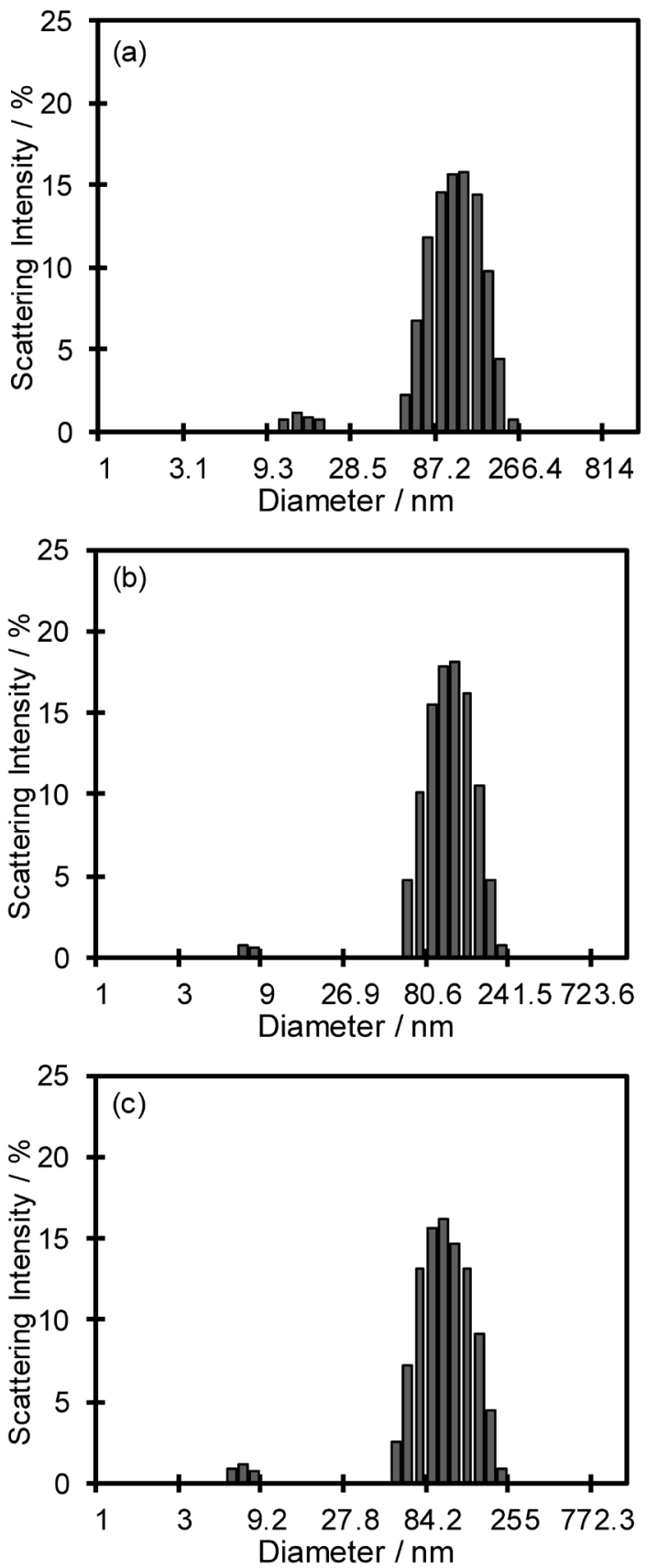

Fig. 4. Time Course of Particle Size Distribution of WSF $(50.8 \mu \mathrm{M})$ in Water after (a) Preparation, (b) $7 \mathrm{~d}$, and (c) $14 \mathrm{~d}$

to its higher interaction with cell membranes because WSF has a cationic moiety in a molecule. However, WSF solutions below $20 \mu \mathrm{M}$ showed insignificant effects on the cell viability in the dark, whereas exhibited the markedly higher cytotoxicity by the photoirradiation indicating a high photodynamic activity at lower concentrations (Fig. 5). As a result of tetrasodium $\alpha, \alpha^{\prime}$-(anthracene-9,10-diyl)bis(methylmalonate) (ABMM) bleaching method, ${ }^{21,22}$ it was confirmed that singlet oxygen of reactive oxygen species (ROS) was generated from WSF by light irradiation, and so that the photodynamic activity of WSF was considered to be caused by ROS.

In conclusion, WSF was shown to form aggregates with concentration-dependent particle size in aqueous medium, exhibiting photodynamic activity at lower concentrations

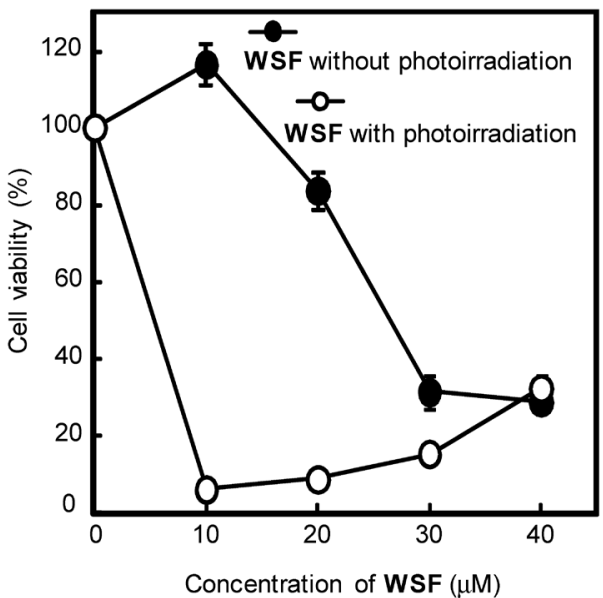

Fig. 5. Dose-Dependent Photodynamic Activity of WSF for A549 Cells Each point represents the mean \pm S.E. of 6 experiments.

and thus being a promising photosensitizer for photodynamic therapy.

\section{Experimental}

General Methods and Materials ${ }^{1} \mathrm{H}-\mathrm{NMR}$ spectra were recorded on a JEOL ECS-400 instrument. Chemical shifts are reported in parts per million ( $\mathrm{ppm}$ ) relative to a tetramethylsilane internal standard $(0.0 \mathrm{ppm}) .{ }^{1} \mathrm{H}-\mathrm{NMR}$ data are reported as follows: Chemical shift $(\delta \mathrm{ppm})$, integration, multiplicity, and coupling constant $(\mathrm{J}, \mathrm{Hz}),{ }^{13} \mathrm{C}-\mathrm{NMR}$ data are reported as follows: chemical shift $(\delta \mathrm{ppm})$. Multiplicities are reported using the following abbreviations: s, singlet; $d$, doublet; $t$, triplet; q, quartet; m, multiplet; and br, broad. Only the strongest and/or structurally relevant IR peaks are reported $\left(\mathrm{cm}^{-1}\right)$ on JASCO FT/IR-7000. All mass spectra were measured on a Bruker Autoflex II matrix-assisted laser desorption/ionizationtime-of-flight (MALDI-TOF) mass spectrometer. Column chromatography was performed using silica gel (BW-300 Fuji Silysia Chemical, Ltd., Japan). Analytical thin layer chromatography was performed on aluminum plates pre-coated with silica gel (Merck, TLC Silica gel $60 \mathrm{~F}_{254}$ ). Dynamic light scattering was measured by Otsuka Electronics Co., Ltd. (Japan) DLS-8000HL. UV-Vis spectra were recorded on Hitachi U-2000.

\section{Synthetic Procedures}

3 -(N-Methylfullero[1,2-c]pyrrolidin-2-yl)-1-(3,6,9,12tetraoxatridecyl)pyridin-1-ium Chloride (WSF)

Under $\mathrm{N}_{2}$ atmosphere, a solution of fulleropyroridine derivative $4^{10)}(299 \mathrm{mg}, 0.35 \mathrm{mmol})$ in dry chlorobenzene $(5 \mathrm{~mL})$ was treated with a solution of pegylation reagent $1(235 \mathrm{mg}$, $0.60 \mathrm{mmol})$ in the same solvent $(10 \mathrm{~mL})$ and stirred at $85^{\circ} \mathrm{C}$ for $24 \mathrm{~h}$. The reaction mixture was evaporated and taken up in diethyl ether, and the residue was purified by column chromatography. $4(6 \mathrm{mg})$ was recovered from the chloroform-ethyl acetate $(5: 1)$ eluate, whereas precursor $5(372 \mathrm{mg}, 85 \%)$ was obtained from the chloroform-methanol $(5: 1)$ eluate and reprecipitated in chloroform-diethyl ether.

Anion exchange resin $(50 \mathrm{~g})$ was sequentially washed with water $(3 \times 250 \mathrm{~mL}), 1 \mathrm{wt} \%$ aqueous $\mathrm{HCl}(250 \mathrm{~mL})$, ionexchanged water $(3 \times 250 \mathrm{~mL})$, methanol $(250 \mathrm{~mL})$, and ionexchanged water $(3 \times 250 \mathrm{~mL})$. After the resin was packed in the column, as solution of $\mathbf{5}(187 \mathrm{mg}, 0.15 \mathrm{mmol})$ in methanol 
(75 mL) was applied, affording WSF (162 mg, quant.) as a dark brown solid. $\mathrm{Mp}>300^{\circ} \mathrm{C}$. IR $(\mathrm{KBr}): 2868(\mathrm{CH}), 1108$ $(\mathrm{C}-\mathrm{O}-\mathrm{C}), 526 \mathrm{~cm}^{-1}(\mathrm{C} 60) .{ }^{1} \mathrm{H}-\mathrm{NMR}\left(400 \mathrm{MHz}, \mathrm{CDCl}_{3}\right) \delta: 2.87$ $\left(3 \mathrm{H}, \mathrm{s}, \mathrm{N}-\mathrm{CH}_{3}\right), 3.33\left(3 \mathrm{H}, \mathrm{s}, \mathrm{CH}_{3}-\mathrm{O}\right), 3.43-3.69\left(12 \mathrm{H}, \mathrm{m}, \mathrm{CH}_{2}\right.$ in ethylene glycol unit), 3.91-4.13 $\left(2 \mathrm{H}, \mathrm{m}, \beta-\mathrm{CH}_{2}\right), 4.42,5.03$ (each $1 \mathrm{H}, \mathrm{d}, J=9.6 \mathrm{~Hz}, 5-\mathrm{H}), 5.36\left(3 \mathrm{H}\right.$, br s, $\left.2-\mathrm{H}, \alpha-\mathrm{CH}_{2}\right), 8.13$ $\left(1 \mathrm{H}, \mathrm{dd}, J=6.5,7.5 \mathrm{~Hz}, 5^{\prime}-\mathrm{H}\right), 8.92(1 \mathrm{H}$, brs, 4'-H), $9.81(2 \mathrm{H}$, brs, $\left.2^{\prime}, 6^{\prime}-\mathrm{H}\right) .{ }^{13} \mathrm{C}-\mathrm{NMR}\left(100.5 \mathrm{MHz}, \mathrm{CDCl}_{3}\right) \delta$ : $39.95\left(\mathrm{~N}-\mathrm{CH}_{3}\right)$, $59.04\left(\mathrm{CH}_{3}-\mathrm{O}\right), 68.91$ (3 or $\left.4-\mathrm{C}\right), 69.63,69.86,70.11,70.39$, 70.48, 70.63, 71.86, $\left(\mathrm{CH}_{2}\right.$ in ethylene glycol unit), 76.23, (3 or $4-\mathrm{C}), 127.78,135.71,135.74,136.79,137.97,138.96,139.68$, $140.29,140.39,140.51,141.52,141.69,141.78,141.88,142.04$, $142.07,142.10,142.29,142.58,142.74,142.78,142.87,143.17$, $143.24,144.28,144.50,144.54,144.81,145.12,145.19,145.22$, $145.28,145.46,145.48,145.61,145.63,145.80,146.02,146.09$, $146.21,146.26,146.32,146.35,146.46,146.52,147.36,147.49$, 151.01, 152.72, $155.40\left(\mathrm{C}_{60}\right)$. MALDI-TOF-MS (dithranol) $\mathrm{m} / \mathrm{z}$ $1045\left([\mathrm{M}-\mathrm{Cl}]^{+}\right)$.

Conflict of Interest The authors declare no conflict of interest.

Supplementary Materials The online version of this article contains supplementary materials.

\section{References}

1) Takenaka S., Yamashita K., Takagi M., Hatta T., Tsuge O., Chem. Lett., 28, 321-322 (1999).

2) Maggini M., Scorrano G., Prato M., J. Am. Chem. Soc., 115, $9798-$ 9799 (1993)

3) Tollas S., Bereczki I., Borbás A., Batta G., Vanderlinden E., Naesens L., Herczegh P., Bioorg. Med. Chem. Lett., 24, 2420-2423 (2014).

4) Tokuyama H., Yamago S., Nakamura E., Shiraki T., Sugiura Y., J. Am. Chem. Soc., 115, 7918-7919 (1993).

5) Friedman H. S., DeCamp L. D., Sijbesma P. R., Srdanov G., Wudl F., Kenyon L. G., J. Am. Chem. Soc., 115, 6506-6509 (1993).

6) Mashino T., Nishikawa D., Takahashi K., Usui N., Yamori T., Seki
M., Endo T., Mochizuki M., Bioorg. Med. Chem. Lett., 13, 43954397 (2003).

7) Deryabin G. D., Davydova K. O., Yankina Z. H. Z., Vasilchenko S. A., Miroshnikov A. S., Kornev B. A., Ivanchikhina V. A., Troshin A. P., J. Nanomater., 2014, 907435 (2014).

8) Tabata Y., Murakami Y., Ikada Y., Fullerene Sci. Technol., 5, 9891007 (1997).

9) Yano S., Naemura M., Toshimitsu A., Akiyama M., Ikeda A., Kikuchi J., Shen X., Duan Q., Narumi A., Inoue M., Ohkubo K., Fukuzumi S., Chem. Commun., 51, 16605-16608 (2015).

10) Wang I. C., Tai L. A., Lee D. D., Kanakamma P. P., Shen C. K.-F., Luh T.-Y., Cheng C. H., Hwang K. C., J. Med. Chem., 42, 4614 4620 (1999).

11) Bosi S., Feruglio L., Milic D., Prato M., Eur. J. Org. Chem., 2003 4741-4747 (2003).

12) Irie K., Nakamura Y., Ohigashi H., Tokuyama H., Yamago S., Nakamura E., Biosci. Biotechnol. Biochem., 60, 1359-1361 (1996).

13) Aroua S., Tiu V. G. E., Ishikawa T., Yamakoshi Y., Helv. Chim. Acta, 99, 805-813 (2016).

14) Verma S., Hauck T., El-Khouly E. M., Padmawar A. P., Canteenwala T., Pritzker K., Ito O., Chiang Y. L., Langmuir, 21, 3267-3272 (2005).

15) Andersson T., Nilsson K., Sundahl M., Westman G., Wennerström O., J. Chem. Soc. Chem. Commun., 1992, 604-606 (1992).

16) Iohara D., Hirayama F., Kansui H., Aoshima H., Yamana S., Yano M., Kitaguchi J., Takashima S., Uekama K., Chem. Lett., 38, 11041105 (2009)

17) Maeda H., Wu J., Sawa T., Matsumura Y., Hori K., J. Control. Release, 65, 271-284 (2000).

18) Maeda H., Adv. Enzyme Regul., 41, 189-207 (2001).

19) Maeda H., Tsukigawa K., Fang J., Microcirculation, 23, 173-182 (2016).

20) Takenaka S., Yamashita K., Takagi M., Hatta T., Tanaka A., Tsuge O., Chem. Lett., 28, 319-320 (1999).

21) Ikeda A., Mae T., Ueda M., Sugikawa K., Shigeto H., Funabashi H., Kuroda A., Akiyama M., Chem. Commun., 53, 2966-2969 (2017).

22) Kuznetsova A. N., Gretsova S. N., Yuzhakova A. O., Negrimovskii M. V., Kaliya L. O., Luk'yanets A. E., Russ. J. Gen. Chem., 71, 36-41 (2001). 